\title{
Metachromatic leucodystrophy (MLD) in a patient with a constitutional ring chromosome
}

\section{2}

\author{
M B Coulter-Mackie, J Rip, M D Ludman, J Beis, D E C Cole
}

\begin{abstract}
Metachromatic leucodystrophy (MLD) is an autosomal recessive lysosomal storage disease resulting from a severe deficiency of arylsulphatase $A$. The arylsulphatase $A$ gene is located on chromosome 22 at q13.3. An MLD patient is described who carries a common splicing mutation (" $I$ " allele) and a de novo ring 22 deleted for the arylsulphatase $A$ gene. The father was determined to be a heterozygous carrier of the "I" allele and the mother a heterozygous carrier of the arylsulphatase $A$ pseudodeficiency allele. The ring 22 was shown by Southern blotting to be deleted in one copy of the arylsulphatase $A$ gene. Minisatellite analysis showed the extent of the deletion and confirmed the biparental inheritance of chromosome 22 sequences. The carrier status of the parents and the patient's 46,XX,r(22) karyotype complicated the initial diagnosis in this family. However, the causal relationship of the ring 22 and MLD have implications for the recurrence risk in this family.
\end{abstract}

\section{( $\mathcal{H}$ Med Genet 1995;32:787-791)}

Metachromatic leucodystrophy (MLD) is a neurodegenerative lysosomal storage disease resulting from a deficiency of activity of arylsulphatase A (ASA, EC 3.1.6.1), an enzyme involved in the normal catabolism of cerebroside sulphatide. MLD is characterised by accumulation of cerebroside sulphatide especially in the myelin forming cells of the CNS. ${ }^{1}$

The ASA gene has been mapped to chromosome 22q13.3 and its complete sequence determined. ${ }^{2} \mathrm{~A}$ variety of mutations have been reported. ${ }^{3}$ In the present context the most significant are the "I" allele ${ }^{4}$ and the pseudodeficiency allele. ${ }^{5}$ The infantile onset "I" allele consists of a composite of a $G \rightarrow A$ transition at the +1 position of intron 2 ("I- 1 "), a trp 193 cys mutation in exon 3 ("I-2"), and a thr391ser in exon 7 ("I-3"). The splicing mutation is the deleterious mutation. The exon 3 "I-2" mutation is usually found in association with "I-1" but has no effect on enzyme activity. The "I- 3 " is a common polymorphism found in up to $54.4 \%$ of the general population. ${ }^{46}$ ASA pseudodeficiency is a situation where ASA activity is significantly reduced without any clinical or biochemical evidence of disease. ${ }^{7}$ Pseudodeficiency carriers occur at 10 to $20 \%$ in the general population. ASA activity can be reduced to about $15 \%$ of normal in homozygotes. A complex of two mutations has been implicated in the pseudodeficiency, a glycosylation site mutation (asp350ser) affecting the third glycosylation site of the enzyme and an $A \rightarrow G$ in the first poly $A$ addition signal. ${ }^{5}$ The former results in loss of a glycosylation site but appears to have little effect on ASA production or activity. The latter results in up to $80 \%$ reduction in ASA activity.

The map location of the ASA gene renders it vulnerable to deletion in chromosome 22 terminal deletions and ring formations. Indeed, several cases of such deletion of the ASA gene have been documented. ${ }^{8-11}$ However, the concomitant occurrence of ring 22 and a severe MLD allele has not previously been reported. We report such a case here. The occurrence of this chromosome rearrangement as one of the alleles in this MLD patient practically eliminates the risk of MLD in future offspring of this family.

\section{Materials and methods}

CASE REPORT

This female child was born to non-consanguineous parents. She showed delayed development in her first year and was investigated for deafness at 14 months. Unusual physical features including large ears, high forehead, upward slanting eyes, micrognathia, large extremities, and broad hands with short phalanges were noted at that time. She also had spina bifida occulta with a sacral dimple. Karyotype investigation showed a possible ring chromosome 22 in all cells examined. This was later confirmed in two subsequent karyotype studies. A partial spread of metaphase chromosomes from cultured fibroblasts is shown in fig 1. Neither parent showed the ring 22 formation. Because the child's condition was worsening more rapidly than would be expected from the ring chromosome alone, she was investigated for the possibility of metabolic errors. Enzymatic assay of arylsulphatase A in fibroblast extracts gave a diagnosis of MLD when the child was 2 years 3 months. She deteriorated rapidly becoming decerebrate by the age of 2 years 4 months and died at 2 years 10 months.

\section{MATERIALS}

Taq polymerase was purchased from Promega. ID Pol, a heat stable DNA polymerase from Thermus flavus, was obtained from ID Labs Inc (London, Ontario). Restriction enzymes were
Received 15 March 1995 Revised version accepted for 24 May 1995 


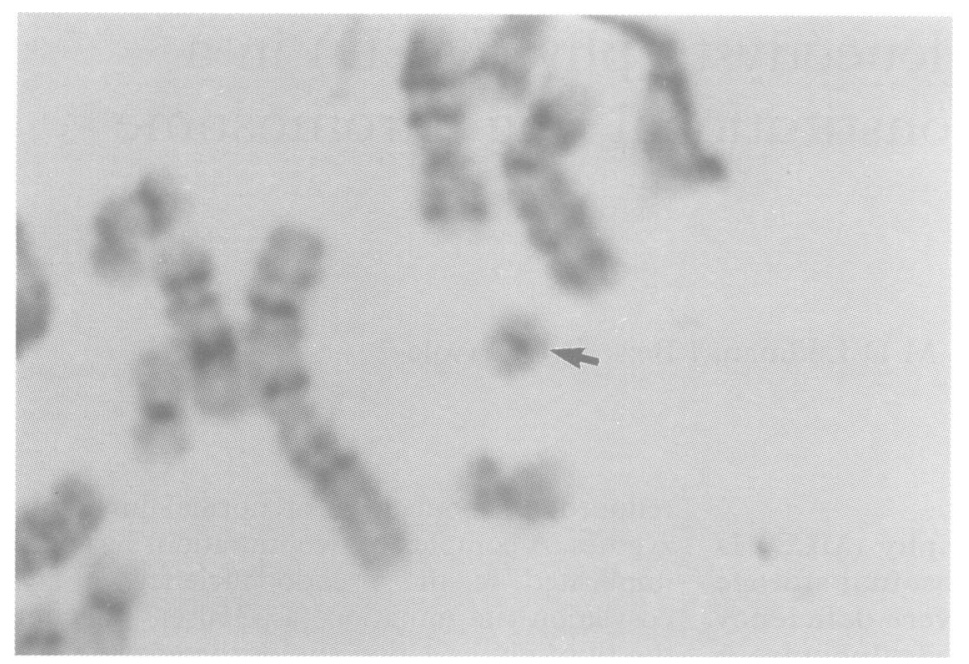

Figure 1 Partial spread of metaphase chromosomes. Trypsin-giemsa chromosomes were prepared by standard cytogenetic techniques. The ring 22 is indicated by an arrow. All other chromosomes were accounted for and normal.

from Pharmacia Biotech (Baie d'Urfé, Quebec), New England Biolabs (Mississauga, Ontario), or Boehringer Mannheim Canada (Laval, Quebec). $\left[\alpha-{ }^{32} \mathrm{P}\right] \mathrm{dCTP}$ (specific radioactivity $3000 \mathrm{Ci} / \mathrm{mmol}$ ) was from Amersham Canada. MapPairs ${ }^{\mathrm{TM}}$ for minisatellite analysis were purchased from Research Genetics (Huntsville, Alabama). A USB Random Primed DNA Labelling kit was purchased from Amersham Canada.

\section{DETERMINATION OF ASA ACTIVITY IN}

FIBROBLAST EXTRACTS

Fibroblast cultures were grown under standard conditions and harvested at about $75 \%$ confluence for assay. Cells were homogenised and cell free supernatants were used in assays with a p-nitrocatechol sulphate substrate in an assay specific for ASA (J Rip and B A Gordon, manuscript in preparation) modified from Baum et al. ${ }^{12}$

\section{POLYMERASE CHAIN REACTION (PCR)}

AMPLIFICATION

The following oligonucleotide primers are from a series designed for screening for common mutations in the ASA gene and were used in the PCR amplifications described below and in table 1 :

(3) 5' CGCGGAATTCTTGATGGCGAACTGAGTGAC 3'

(4) 5' CGCGTCTAGAACGCTCTGCAAAGCTCTGCC 3

(6) 5' CTATGGCCAATTCTGTGCACAGGGCAAG 3'

(10) $5^{\prime}$ CACAGAATTCAGGGACTC'TGTGACTTGTC

(11) 5' TGTCACAGCTGCAAGTCTCCACTGGTGGTA 3'

(12) 5' GGGCTGAGGTCAAAGCCATCCAAGCTGTCA 3'
(15) $5^{\prime}$ ATCAGGGCTTCCATCGATTTCTAG 3'

(16) 5' TCACAGCCACCGTCGCAAGGAGTG 3

(17) $5^{\prime}$ ATTGCCCAGATCCCCATGCCTGAG $3^{\prime}$

(19) 5' CGAAGGTCACAGCTGCGTCTAAC 3'.

Restriction enzyme recognition sites were incorporated into primers $3,4,6$, and 10 at the $5^{\prime}$ ends to facilitate cloning. Mismatched bases introduced in primers 11 and 12 to generate new restriction sites in the PCR product are underlined. All primers were synthesised using phosphoramadite chemistry on an automated DNA synthesiser.

PCR amplifications were performed using published procedures. ${ }^{13}$ Primers were added to a final concentration of $1 \mu \mathrm{mol} / 1$ each. Substrate DNA was added at $1 \mu \mathrm{g} / 100 \mu \mathrm{l}$. Taq and ID Pol polymerases were used interchangeably at $2.5 \mathrm{U} / 100 \mu \mathrm{l}$ and 0.75 to $1 \cdot 25 / 100 \mu \mathrm{l}$ respectively. $\mathrm{MgCl}_{2}$ concentration was at $1.5 \mathrm{mmol} / 1$ unless otherwise stated. Cycling parameters were: denaturation $-94^{\circ}$, two minutes; annealing temperature as specified in table $1,1.5$ minutes; extension $-72^{\circ}$, two minutes; 30 cycles followed by a seven minute extension at $72^{\circ}$. All reaction mixtures were overlaid with mineral oil and amplification initiated by addition of polymerase to a hot $\left(94^{\circ}\right)$ reaction mixture ("hot start"). RT-PCR was performed using fibroblast mRNA MMulv reverse transcriptase as previously described. ${ }^{14}$

Amplification for minisatellite analysis was performed as above with incubation times shortened to 45 seconds for denaturation and 30 seconds for annealing and extension and using MapPairs ${ }^{\mathrm{TM}}$ oligonucleotides ${ }^{1516}$ specific for chromosome 22 . An annealing temperature of $60^{\circ}$ was used for all primer pairs except TOPIP2 where $50^{\circ}$ was used. Products were labelled during the amplification with $\left[\alpha-{ }^{32} \mathrm{P}\right]$ dCTP (approximately $0.5 \mu \mathrm{Ci}$ per $10 \mu \mathrm{l}$ reaction volume), separated in a sequencing type polyacrylamide gel at $1500 \mathrm{~V}$, and detected by autoradiography.

\section{SOUTHERN BLOT ANALYSIS}

DNA probes were excised from plasmids and labelled with $\left[\alpha-{ }^{32} \mathrm{P}\right] \mathrm{dCTP}$ by random primed labelling. Genomic DNA samples ( $5 \mu \mathrm{g}$ each) were digested with HindIII, and subjected to electrophoresis in $0.8 \%$ agarose, capillary blotting in neutral buffer, and hybridisation with probe by standard methods. ${ }^{17}$

\section{Results}

ASA ACTIVITY IN FIBROBLAST EXTRACTS

Fibroblast extracts from the patient, her parents, and controls were analysed for ASA ac-

Table 1 PCR primers and restriction enzymes used to detect "I" and pseudodeficiency mutations in the ASA gene

\begin{tabular}{llllll}
\hline Site & Primers & $\begin{array}{l}P C R \text { product size } \\
(b p)\end{array}$ & $\begin{array}{l}\text { Annealing } \\
\text { temperature }\end{array}$ & Restriction enzyme & $\begin{array}{l}\text { Restriction site in } \\
\text { normal sequence* }\end{array}$ \\
\hline "I-1" & & 220 & $60^{\circ}$ & MvaI & + \\
"I-1/I-2"† & $15 / 16$ & 738 & $65^{\circ}$ & MvaI & $+/+$ \\
"I-3"/glycosylationt & $10 / 4$ & 860 & $68^{\circ}$ & BsrI & $+/-$ \\
Poly A & $3 / 19$ & 147 & $65^{\circ}$ & RsaI & - \\
Glycosylation & $17 / 11$ & 157 & $60^{\circ}$ & MaeIII & - \\
\hline
\end{tabular}

*Normal sequence as per accession number X52150 (EMBL)

tSimultaneous detection of the two sites. 
Table 2 ASA enzyme activity in fibroblast extracts*

\begin{tabular}{lll}
\hline Sample & $\begin{array}{l}\text { ASA activity } \\
\text { (nmol/h/mg protein) }\end{array}$ & \% control activity \\
\hline Mother & $17 \cdot 01$ & $44 \cdot 9$ \\
Father & $10 \cdot 14$ & $26 \cdot 8$ \\
Patient & $0 \cdot 009$ & $0 \cdot 02$ \\
Control & $37 \cdot 9$ & \\
Average & $(22 \cdot 3-49 \cdot 6)$ & \\
Range & & \\
\hline
\end{tabular}

${ }^{*}$ Activity measured with p-nitrocatechol sulphate as described in Methods.

tivity as described above. The results shown in table 2 indicate virtually no activity in the patient sample and reduced levels in both parents relative to the control average. This is consistent with a clinical diagnosis of MLD and agreed with earlier results on which the patient's diagnosis was based.

\section{PCR/RESTRICTION ENZYME ANALYSIS}

DNA from family members was tested for the "I-1" mutation using primers 15 and 16 and the restriction enzyme $M v a \mathrm{I}$ as outlined in table 1. Results shown in fig 2A clearly indicated that the father's PCR product was partly cut by $M v a \mathrm{I}$ and thus he is a heterozygous carrier of this mutation. The patient's sample appears to be homozygous for the "I-1" mutation; it was totally uncut. However, the mother's sample was completely cut and therefore she does not carry the "I-1" mutation. This suggests that her daughter is probably deleted in one ASA allele and is actually hemizygous for the "I-1" mutation.

A

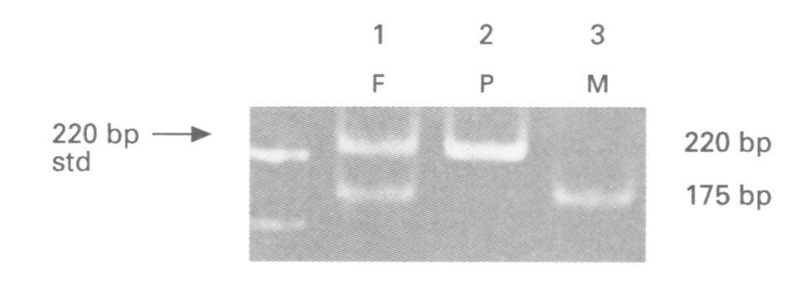

B

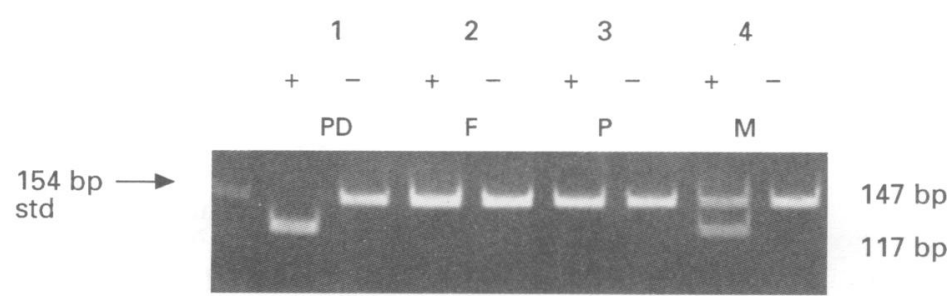

Figure $2 \quad P C R /$ restriction enzyme analysis. Genomic DNA was amplified by PCR and subjected to MvaI digestion. $(A)$ "I-1" allele: lane 1, father $(F)$; lane 2, patient $(P)$; lane 3, mother (M). A $220 \mathrm{bp}$ standard is indicated to the left. The $220 \mathrm{bp}$ abnormal product is not cut by Mval. The $175 \mathrm{bp}$ product results from cutting of a normal $220 \mathrm{bp}$ PCR product by MvaI. (B) Poly A pseudodeficiency mutations: samples are shown \pm addition of Rsal. Sample 1, pseudodeficiency homozygote control (PD); sample 2, father $(F)$; sample 3, patient (P); sample 4, mother (M). The $147 \mathrm{bp}$ normal product is not cut by Rsal. The 117 bp product results from cutting of an abnormal 147 bp product by Rsal. $A 154$ bp standard is indicated on the left.
Further support for this comes from PCR based analyses of the "I-2" and "I-3" polymorphisms and the pseudodeficiency mutations as outlined in table 1 . The "I-1" and "I2 ", and the "I-3" and glycosylation mutations can be detected simultaneously (data not shown). The glycosylation mutation can also be identified independently of the "I-3". Results for the poly A signal mutations are shown in fig 2B. The samples from the father and daughter were not cut by $R s a \mathrm{I}$ indicating that they were both homozygous negative for the mutation. The mother's sample was partly cut by RsaI indicating that she is a carrier of the mutation. In summary, the father is heterozygous for all three "I" mutations and homozygous negative for the two pseudodeficiency mutations (glycosylation and poly A). The mother is homozygous negative for all three "I" mutations and a heterozygous carrier for the two pseudodeficiency mutations. The patient carries the three "I" mutations but not the two pseudodeficiency mutations. The finding of a pseudodeficiency allele in the mother accounts for her decreased level of ASA enzyme activity. Clearly none of the mother's ASA markers, neither her pseudodeficiency mutations, nor her normal sequence at the sites of the "I" mutations, have been passed to her daughter, consistent with a complete deletion of the gene.

\section{SOUTHERN BLOT ANALYSIS}

DNA from family members was cut with restriction enzymes and subjected to agarose gel electrophoresis and Southern blot analysis. Results of HindIII digestion and hybridisation with a probe for the ASA cDNA are shown in fig 3. Visually the patient's sample appears to be about half the density of that of the parents,

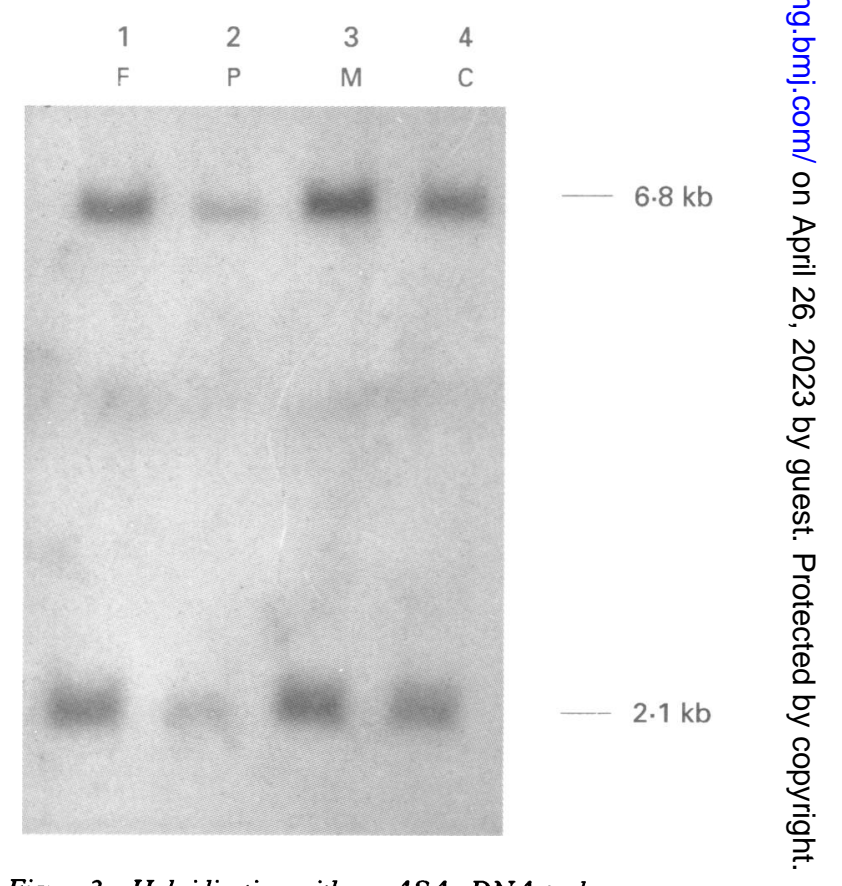

Figure 3 Hybridisation with an $A S A$ CDNA probe.

Lane 1 , father $(F)$; lane 2, patient $(P)$; lane 3 , mother $(M)$; lane 4, control $(C)$. Sizes of the restriction fragments are given in $k b$. 


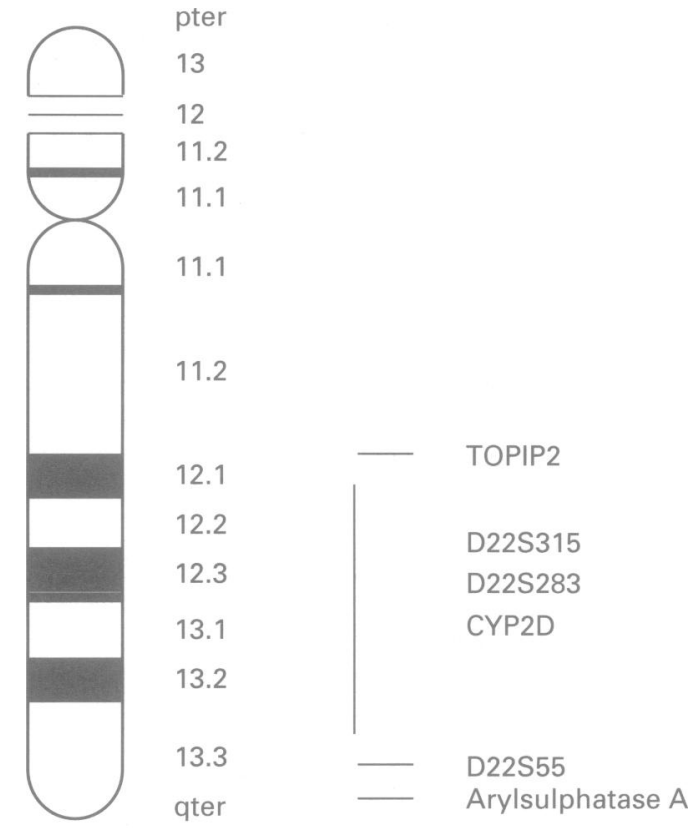

Figure 4 An ideogram of chromosome 22 showing the approximate locations of the markers described. ${ }^{10151618}$

suggestive of deletion of one allele. Analysis of the same blot with a probe for the proximally located D22S55 site, $\mathrm{pH} 91^{18}$ (data not shown), gave a similar result with a single band of $5.5 \mathrm{~kb}$, again consistent with a deletion and suggesting that the loss of material from $\mathrm{C} 22 \mathrm{q}$ extends proximal to the ASA gene at least as

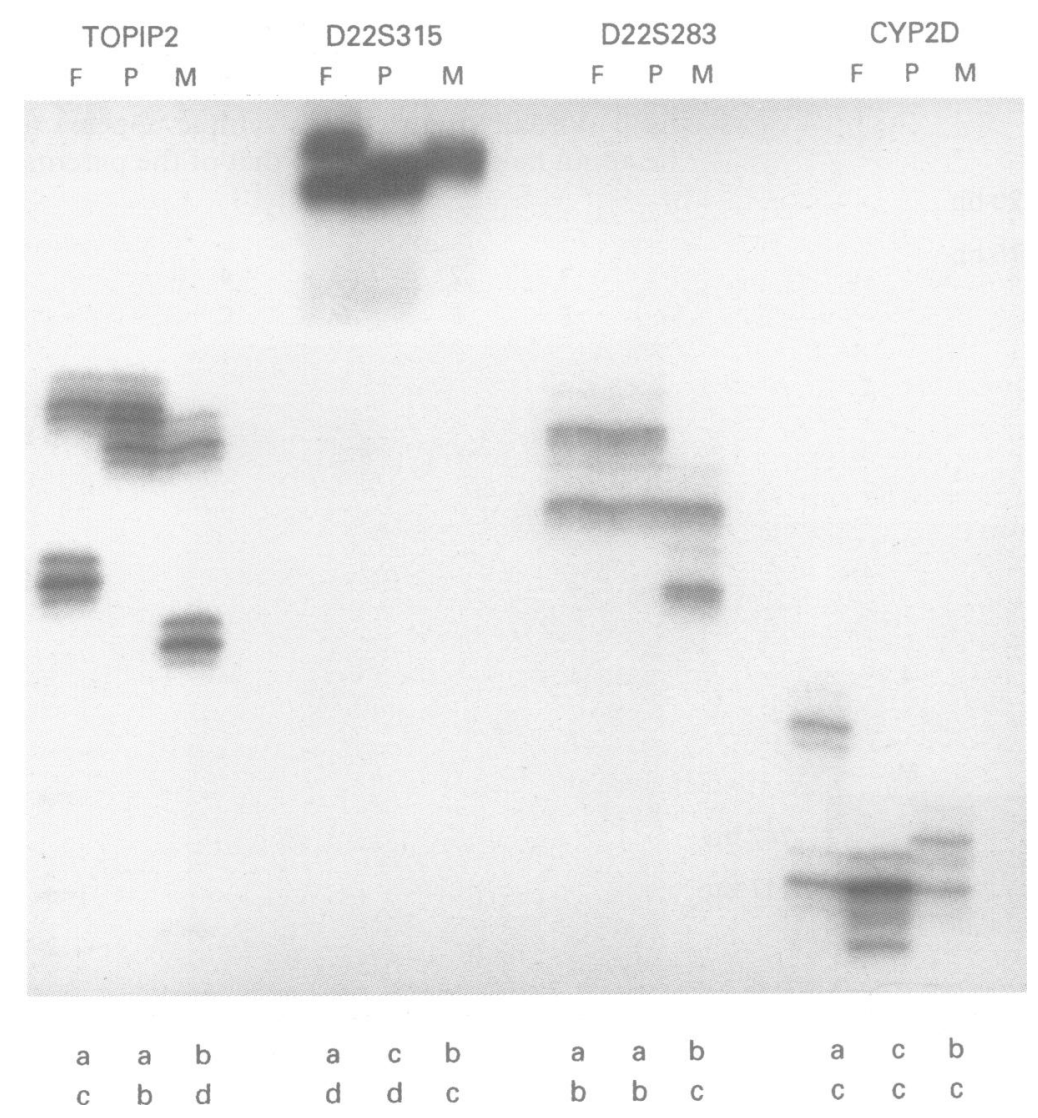

Figure 5 Minisatellite analysis: $2 \mu$ l aliquots of $10 \mu \mathrm{l}$ reactions were loaded onto the gel. The samples are from the father $(F)$, patient $(P)$, and mother $(M)$ respectively in each set of three. Alleles are designated $a, b, c$, and $d$. far as D22S55. The approximate location of $\mathrm{D} 22 \mathrm{~S} 55$ relative to the ASA gene is shown in fig 4 .

\section{MINISATELLITE ANALYSIS}

Minisatellite analysis was performed on this family and the results are shown in fig 5 . Approximate locations of all markers used are shown in fig 4. Amplification with the primers for the markers D22S315 and TOPIP2 clearly indicated inheritance of unique alleles from both parents in the child. The markers D22S283 and CYP2D also showed probable inheritance from both parents; however a common allele is shared by all three family members. Thus, these markers are proximal to the breakpoints involved in the ring formation. These data, in conjunction with the "I" allele inheritance pattern, confirm that there is biparental inheritance of chromosome 22 sequences and that the ring with the deletion is of maternal origin.

ASA SPECIFIC MRNA TRANSCRIPTION

The production of ASA specific mRNA in the patient was tested using RT-PCR as described in Methods. Virtually no product was detectable in the child's sample although appropriate sized products were detected when primers for an unrelated gene (aspartylglucosaminidase) on another chromosome were used (data not shown). These results are consistent with the expectation of essentially no functional ASA specific mRNA where one allele is deleted and the other carries a major splicing mutation.

\section{Discussion}

We have reported here a case of a female patient with MLD who has inherited a paternal chromosome 22 carrying the infantile onset "I" allele and has a de novo constitutional ring chromosome 22 of maternal origin, deleted for the ASA gene. The deleterious "I-1" mutation is a splicing defect $^{4}$ and is not expected to produce any active enzyme of functional mRNA. The deletion of the other ASA allele would also preclude production of functional mRNA. This was indeed the case, as no RTPCR products of appropriate size were detectable in this child although the mRNA was able to support transcription of an unrelated cDNA and PCR product.

A typical clinical picture of a patient with a constitutional ring 22 includes significant mental retardation, microcephaly, growth failure, hypotonia, ${ }^{19}$ and perhaps a predisposition to meningioma formation. ${ }^{20-22}$ In this particular case the child was referred for cytogenetic analysis because of dysmorphic features, several of which have been noted in other cases of ring 22 . De novo ring chromosomes affecting chromosome 22 are relatively rare, comprising approximately 9 to $10 \%$ of all constitutional autosomal rings. ${ }^{23}$ Autosomal rings occur in about 1/50 000 live births although they have also been detected as isolated findings in men- 
ingioma tissue. The formation of the ring is thought to involve deletion of material from the telomeres of the chromosome and rejoining. Loss of the ASA gene is not an unexpected event in such circumstances given its location at $22 \mathrm{q} 13.3$. Indeed, loss of one ASA allele has been documented in at least three other cases of terminal deletion or ring formation of chromosome 22 using either reduced enzyme activity $^{911}$ or molecular detection ${ }^{811}$ as the criterion. In the case presented here, the coinheritance of a severe allele from the father resulted in infantile onset MLD.

Children with infantile onset MLD usually develop clinical signs between the ages of 15 months and 2 years. ${ }^{1}$ They lose the ability to walk or stand and show ataxia, weakness, and progressive spastic quadriplegia. Blindness, seizures, and loss of speech are commonly seen. Neurological function declines rapidly to a decerebrate state and the disease culminates in death usually within one to seven years of onset. There are not usually striking dysmorphic features associated with MLD.

A metabolic error was not initially suspected in this child. It was not until it became obvious that she was deteriorating much more rapidly than would have been expected for ring 22 alone that she was investigated for possible metabolic errors. Subjects with documented ring 22 alone ${ }^{92021}$ have usually survived longer. Those with one deleted arylsulphatase A gene would not have been expected to display any signs of MLD since they would have had a normal copy of the ASA gene on the other chromosome and therefore would have had heterozygote carrier levels of ASA enzyme activity and none of the clinical problems associated with MLD.

In considering this family's risk for future pregnancies, there is a $25 \%$ chance of having a child with a combination of the father's "I" allele and the mother's pseudodeficiency allele but this would not result in MLD. Compound heterozygotes for MLD and pseudodeficiency alleles have been identified in other laboratories $^{24}$ as well as our own and are usually without any clinical symptoms. However, the risk for late onset or neuropsychiatric disorders associated with this combination of alleles remains a contentious issue. ${ }^{2425}$ Such a combination of alleles would also complicate prenatal diagnosis by enzymological means alone since it is not always possible to distinguish unequivocally a compound heterozygote fetus from one that is affected with MLD. DNA analysis would be necessary to provide an unambiguous result. The risk for a second ring chromosome event in this family is very small and thus there is essentially no risk of a second MLD child.

This research was supported by grants to MBC-M from the British Columbia Health Research Foundation and the CPR Research Initiatives Program (London, Ontario). We are grateful to Dr V Gieselmann (Institut für Biochemie, Göttingen, Ger- many) for the ASA cDNA probe and to $\mathrm{Dr} \mathrm{H}$ McDermid (University of Alberta, Edmonton, Alberta) for the $\mathrm{pH} 91$ probe; University of Alderta, Edmonton, Alser to Drs G A Mackie (Department of Biochemistry and Molecular Biology, University of British Columbia), B A Gordon (CPRI, London, Ontario), and D A Applegarth (Biochemical Disease Laboratory, BC Children's Hospital, Vancouver, BC) for helpful discussions; Drs H Cook, P Welch, and B Zwicker (Atlantic Research Centre, Dalhousie University, Halifax, Nova Scotia) for providing the cell lines and clinical information. Technica assistance by Ms Liane Gagnier is appreciated.

1 Kolodny EH, Fluharty AL. Metachromatic leukodystrophy and multiple sulfatase deficiency: sulfatide lipidosis. In Scriver CR, Beaudet AL, Sly WS, Valle D, eds. The metabolic basis of inherited disease. 7th ed. Vol 2. New York McGraw-Hill, 1995:2693-739.

2 Kreysing J, Gieselmann V. Structure of the arylsulfatase A gene. Eur F Biochem 1990;191:627-31.

3 Gieselmann V, Zlogotora J, Harris A, Wenger D, Morris JP. Molecular genetics of metachromatic leukodystrophy. Hum Mutat 1994;4:233-42.

4 Polten A, Fluharty AL, Fluharty CB, Kappler J, von Figura $\mathrm{K}$, Gieselmann V. Molecular basis of different forms of metachromatic leukodystrophy. $N$ Engl ₹ Med 1991;324: 18-22.

5 Gieselmann V, Polten A, Kreysing J, von Figura K. Arylsulfatase A pseudodeficiency: loss of a polyadenylation signal and n-glycosylation site. Proc Natl Acad Sci USA 1989;86:9436-40.

6 Zlotogora J, Furman-Shaharabani Y, Harris A, Barth ML, von Figura $\mathrm{K}$, Gieselmann V. A single origin for the most von Figura $\mathrm{K}$, Gieselmann V. A single origin for the most frequent mutation causing late infantile metact
leucodystrophy. $₹$ Med Genet 1994;31:672-4.

7 Thomas GH. "Pseudodeficiencies" of lysosomal hydrolases. Am 7 Hum Genet 1994;54:934-40.

8 Tommerup N, Warburg M, Gieselmann V, Hansen BR, Koch J, Petersen GB. Ring chromosome 22 and neurofibromatosis. Clin Genet 1992;42:171-7.

9 Gustavson KH, Aranchibia W, Eriksson U, Svennerholm L. Deleted ring chromosome 22 in a mentally retarded boy. Clin Genet 1986;29:337-41.

10 Nesslinger NJ, Gorski JL, Kurczynski TW, et al. Clinical, cytogenetic, and molecular characterization of seven patients with deletions of chromosome 22q13.3. Am $\mathcal{F}$ Hum Genet 1994;54:464-72.

11 Phelan MC, Thomas GR, Saul RA, et al. Cytogenetic, biochemical, and molecular analysis of a $22 \mathrm{q} 13$ deletion. Am ₹ Med Genet 1992;43:872-6.

12 Baum H, Dodgson KS, Spencer B. The assay of arylsulphatases A and B in human urine. Clin Chim Acta sulphatases A
$1959 ; 4: 453-5$

13 Innis MA, Gelfand DH, Sninsky JJ, White TJ, eds. $P C R$ protocols. A guide to methods and applications. 1st ed. San Diego, CA: Academic Press, 1990.

14 Ainsworth PJ, Coulter-Mackie MB. A double mutation in exon 6 of the $\beta$-hexosaminidase $\alpha$ subunit in a patient with the $\mathrm{B} 1$ variant of Tay-Sachs disease. Am $\mathcal{F}$ Hum Gene 1992;51:802-9.

15 Weissenbach J, Gyapay G, Dib C, et al. A second-generation linkage map of the human genome. Nature 1992;359. 794-801.

$16 \mathrm{NIH} / \mathrm{CEPH}$. A comprehensive genetic linkage map of the human genome. Science 1992;258:67-86.

17 Sambrook J, Fritsch EF, Maniatis T, eds. Molecular cloning: a laboratory manual. 2nd ed. Cold Spring Harbor, NY: a laboratory manual. 2nd ed. Cold Spring Hart

18 Budarf ML, McDermid HE, Sellinger B, Emanuel BS. Isolation and regional localization of 35 unique anIsolation and regional localization of 35 unique anonymous DNA markers for
omics 1991;10:996-1002.

19 Hunter AGW, Ray M, Wang HS, Thompson DR. Phenotypic correlations in patients with ring chromosome 22 . Clin Genet 1977;12:239-49.

20 Petrella R, Levine S, Wilmot PL, Ashar KD, Cassamassima AC, Shapiro LR. Multiple meningiomas in a patient with constitutional ring chromosome 22. Am $\mathcal{F}$ Med Genet 1993 47:184-6.

21 Arinami T, Kondo I, Hamaguchi H, Nakajima S. Multifocal meningiomas in a patient with a constitutional ring chromosome 22. f Med Genet 1986;23:178-80.

22 Tommerup N, Lothe R. Constitutional ring chromosomes and tumour suppressor genes. 7 Med Genet 1992;29:87982 .

23 Wyandt HE. Ring autosomes: identification, familial transmission, causes of phenotypic effects and in vitro mosaicism. In: Daniel A, ed. The cytogenetics of mammalian autosomal rearrangements. New York: Alan R Liss, 1988: autosomal

24 Penzien JM, Kappler J, Herschkowitz N, et al. Compound heterozygosity for metachromatic leukodystrophy and arylsulfatase A pseudodeficiency alleles is not associated with progressive neurological disease. Am $\mathcal{F}$ Hum Gene 1993;52:557-64

25 Sangiorgi S, Ferlini A, Zanetti A, Mochi M. Reduced activity of arylsulfatase $\mathrm{A}$ and predisposition to neurological disorders: analysis of 140 pediatric patients. Am $\mathcal{F}$ Med Genet 1991;40:365-9. 